\title{
Routing Protocols used for CRN : A Survey
}

\author{
Sangita U. Pawar \\ Department of Computer Engineering, \\ MIT Academy of Engineering, \\ Alandi (D), University of Pune, India
}

\author{
S.S. Barve \\ Department of Computer Engineering, \\ MIT Academy of Engineering, Alandi (D), \\ University of Pune, India
}

\begin{abstract}
Cognitive Radio (CR) is an emerging technology in the wireless communication. CR nodes have the capability to change its transmission or reception efficiently without interfering with licensed users. The network formed with CR nodes communicating with each other is called Cognitive Radio Network (CRN). CRN utilizes the unutilized frequency spectrum. Routing in CRN is a main challenge due the rapid changes in the data rates and available channels. In this paper we present the routing protocols used for CRN .We first discuss the routing differences and challenges in CRN. Furthermore we classify the routing protocols depending on the protocol operation.
\end{abstract}

\section{General Terms}

Cognitive Radio, wireless communication, frequency spectrum, challenges for routing in Cognitive Radio Networks, classification based on routing protocols.

\section{Keywords}

CRNs, CRAHNs, Primary Users (PU), Routing, Routing protocols for CRNs, Secondary Users (SU).

\section{INTRODUCTION}

Nowadays wireless communication is rapidly growing up in all the areas of communication. Media for the communication is various wireless devices. These devices offer us the basic as well as the advanced services. To provide these wireless services, the wireless devices are using licensed as well as unlicensed spectrum bands. Licensed bands are allocated for license users for their personal use. While unlicensed bands are left open for unlicensed users (ISM bands $900 \mathrm{MHz}$ and $2.4 \mathrm{GHz}$ ), according to FCC Rules for Unlicensed Wireless Equipment operating in the ISM bands. Advance wireless technologies such as - Wi-Fi/802.11, Blue tooth, digital cordless phones, $3 \mathrm{G}$ and so on are operating on these unlicensed bands. Hence the unlicensed bands are crowded but on the other hand licensed bands are less utilized or not even utilized[1] .Unlicensed bands are so crowded that there is a lack of amount of spectrum to meet the user requirements. To overcome this problem of insufficient amount of spectrum, the concept of Dynamic Spectrum Access is introduced. DARPAs approach on Dynamic Spectrum Access network focuses on the implementation of the policy based intelligent radios known as cognitive radios[2][3].Networks formed using this cognitive radio (CR) nodes are called cognitive radio networks(CRN). CRN can be classified in two types as: 1 . Infrastructure based CR networks 2. Cognitive radio ad hoc networks (CRAHNs). In Infrastructure based CR networks there is a central network entity through which the CR nodes are communicating with each other[4]. In Cognitive radio ad hoc networks (CRAHNs) there is no such a central network entity, rather a CR user can communicate with other CR users through ad hoc connection on both licensed and unlicensed spectrum bands[5].Difference between these two CRNs is shown in the fig. below.

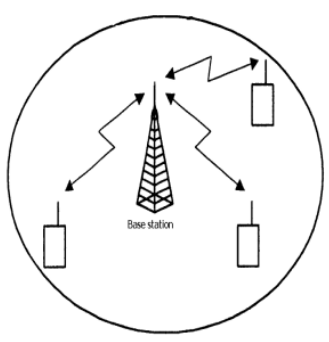

(a)Infrastructure based CR network

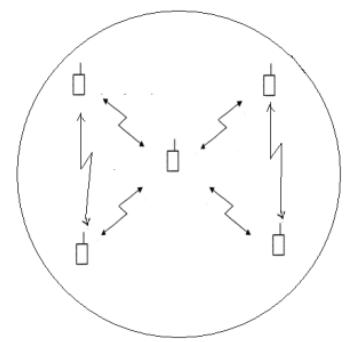

(b) Cognitive radio ad hoc networks (CRAHNs)
Fig 1 : Types of network: (a) infrastructure based CRN and (b) CRAHN.

The main feature of CRAHN is the dynamic channel availability for each node and dynamic topology, due to which there are two main challenges :- 1 . Proper channel assignment so that there can be efficient data routing. 2 . Routing performance without disturbing the Primary user's activities. So routing has the important role to transfer the data from source node to destination node efficiently and effectively. Due to the unexpected behavior of Primary Users , CRAHNs follows dynamic behavior. Due to which, the routing protocols for other wireless networks are not suitable to CRAHN. Therefore, modifications are needed in these protocols for efficient and effective routing in CRN. Some of these routing protocols for CRN are discussed in this paper. The rest of this paper is organized as follows. In Section 2, challenges for routing in CRN are discussed. In section 3 , classification of routing protocols is discussed . In section 4 , the summary of all the routing protocols is presented in terms of tables. Finally paper is concluded in section 5 .

\section{CHALLENGES FOR ROUTING IN CRN:}

The channel availability and data rates are varying continuously in case of CRNs, especially in case of multi hop CRNs. To design a routing scheme for such CRNs is a challenging job. $\mathrm{CR}$ users can access multiple available channels simultaneously, due to which overall network performance is increased and interference on the primary users is decreased. For this feature of CRNs the conventional routing metrics such as hope count, congestion, etc, are not sufficient for routing decision in CRNs [9]. Some challenges for routing in CRN are listed below:- 


\subsection{Link Availability:}

Cognitive Radio Networks uses the licensed band in an opportunistic manner for communication among the CR nodes, using DSA (Dynamic Spectrum Access) [2]. These licensed bands are available to CR nodes for communication, only when these are not used by primary users. Thus we can say that the channel availability is based on geography as well as time. This random channel availability forms random CRN topology, even if all CR nodes are static, not mentioned mobile nature of CRN.

\subsection{Unidirectional Links:}

In wireless networking unidirectional links are rare but in case of CRN , the CR nodes may get the opportunity of transmission in one time duration and there is no guarantee of opportunity for transmission from the another direction. Thus in the true sense it can be said that CRN differs from other wireless networks, at the network layer.

\subsection{Heterogeneity:}

$\mathrm{CRN}$ is generally formed by heterogeneous wireless networks, which is not the case with the typical wireless ad hoc or sensor networks. Inter-system handover is usually required for routing in such heterogeneous wireless networks. Also the links are available for extremely short duration, hence successful networking lies in cooperative relaying among such heterogeneous wireless networks [7].

\subsection{Deafness Problem:}

Deafness problem is nothing but switching of relay nodes among the available channel set whenever the presence of primary user is detected. This activity causes extra delay in CRNs communications [8].

\section{CLASSIFICATION OF ROUTING PROTOCOLS}

There are many routing protocols applicable for wireless networks, but it is not feasible to apply these routing protocols for CRNs, due to their poor performance in dynamic spectrum environment. Routing protocols for CRN are classified according to their operation as shown in the figure below.

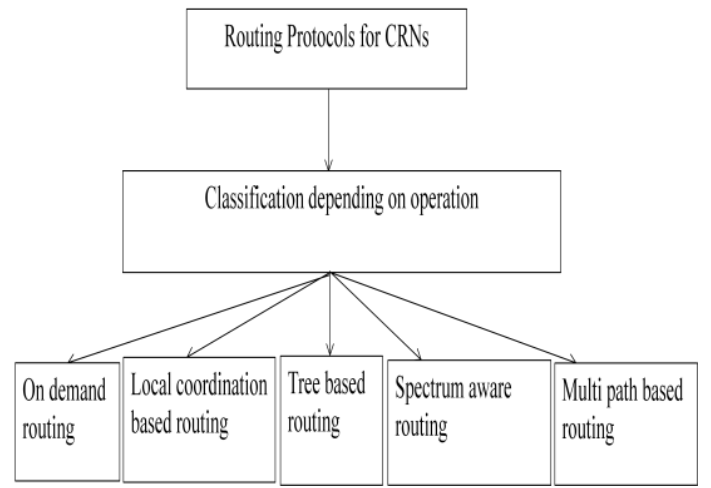

Fig 2: Routing protocols for cognitive radio networks

\subsection{On-demand Routing Protocols}

CRAHNs persist dynamic nature due to the unexpected behavior of Primary Users. Therefore on demand routing is more suitable for CRAHNs rather than the proactive routing. In the on-demand routing protocols, a path is established only when there is active communication taking place, due to which energy consumption is reduced. In wireless ad hoc networks there are two basic on- demand routing protocols used: 1) AODV[10]. 2) DSR[11]. From these two, AODV is more preferred for cognitive wireless networks rather than DSR. Reason behind this is that the route discovery procedure in DSR results in an unpredictable length of control packets and data packets. So that DSR doesn't suit to the irregular behavior of CRNs in the connecting environment. While selecting the routing protocol for CRNs, some modifications are to be done in AODV and DSR, because of the dynamic spectrum environment of CRNs. A simple modification to adopt AODV into CRAHNs environment is by defining a new routing metric with 'spectrum awareness' property. Such protocols are SORP [12], DORP [13]. Following diagrams shows the working of AODV protocol for the network with eight nodes:

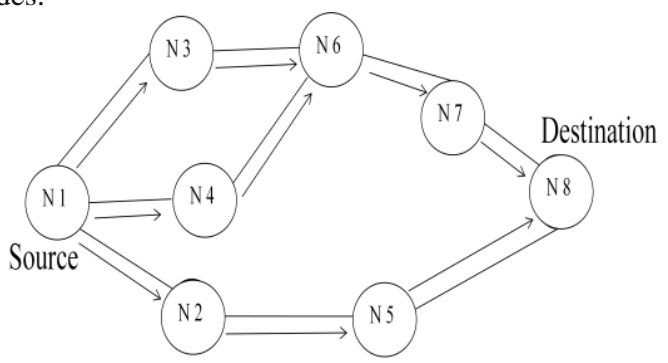

(a) Propagation of the RREQ

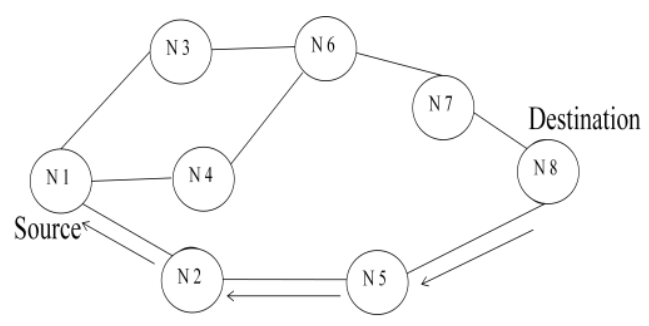

(b) Path of the RREP to the source

Fig 3: Working of AODV

As shown in the figure above, whenever a node wishes to send a packet to destination, then AODV protocol uses two control massages: 1. Route Request (RREQ) and 2. Route Reply (RREP), for Route Discovery process. To control network wide broadcasts of RREQs, the source node use an expanding ring search technique. The forward path sets up in intermediate nodes or relaying nodes in its route table with a lifetime association using RREP. This route table contains the following information:

- Destination

- Next Hop

- Number of hops (metric)

- Sequence number for the destination

- Active neighbors for this route

- Expiration time for the route table entry

When either destination or intermediate node moves, a route error (RERR) is sent to the affected source nodes. When source node receives the (RERR), it can reinitiate route discovery if the route is still needed. Neighborhood information is obtained from broadcast Hello packet. AODV can setup the reverse/forward path pointers and destination/source sequence numbers. Sequence numbers are used as freshness indicator and loop-free guarantee [14]. 


\subsubsection{SORP (Spectrum-Aware On Demand Routing Protocol)}

SORP is the adaptation of ad hoc on-demand distance vector (AODV) protocol, which is discussed above. As discussed before in section 3.1, due to the dynamic environment of CRNs, some modifications are necessarily done in the basic on-demand routing protocol. This modification can be in the form of inserting spectrum-related information, such as spectrum opportunity (SOP), channel usage list, etc., of the SUs into the routing control packets. In case of SORP, this modification is done in the route discovery process as follows: On the control packets (RREQ, RREP, and RERR) , spectrum-related information is piggybacked. That is, the source node inserts its spectrum related information (for example Spectrum Opportunity(SOP)) on RREQ packets. When these RREQ packets are forwarded by relaying / intermediate nodes, these nodes also add their own SOP to it. It is finally decided by destination node that which spectrum band is to be used for transferring data. Destination node assigns the spectrum, place it in RREP and send it back to the source node. In the same manner relaying / intermediate nodes that receive RREP assign the spectrum bands (Figure 4). Thus , size of the packet increases on forwarding of RREQ and RREP with agreement with the hop or distance between the source and destination. Whenever SORP is used for routing in CRNs, the two main terms are to be considered: Switching delay and back off delay. Switching delay is defined as the delay caused by switching among frequency bands. And back off delay is the delay caused by multi-flow interference within a frequency band. Sum of these two delays introduces cumulative delay:

$$
\begin{aligned}
D_{\text {cumulative }}= & D_{\text {switching }} \\
& +D_{\text {backoff }}
\end{aligned}
$$

As SORP focuses on delays, it is suitable for delay-sensitive applications. Delay-motivated on-demand routing protocol (DORP) is another protocol which is the work in continuation with SORP. DORP adds queuing delay caused by the transmission of other flows on the node to the cumulative delay calculation.

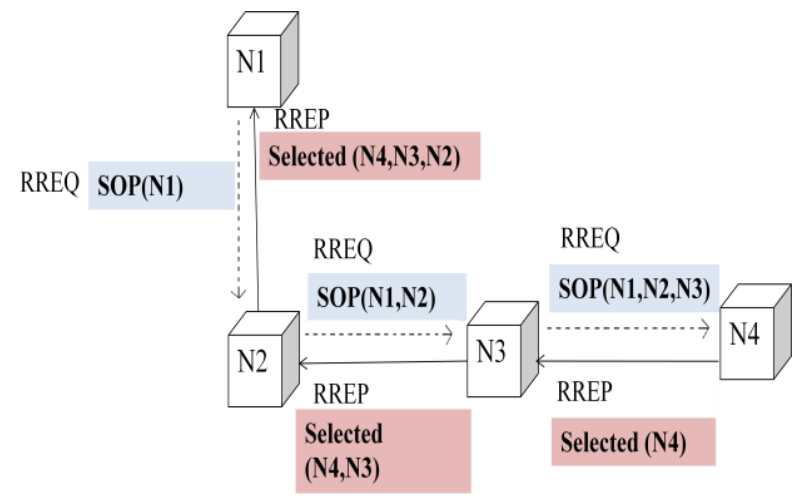

Fig 4: Inserting the spectrum opportunity(sop) into the RREQ and selected spectrum band into the RREP packets.

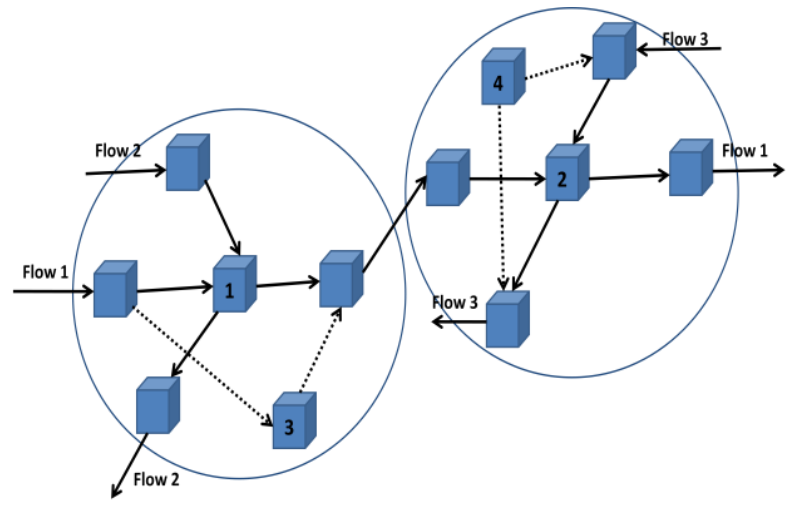

Fig 5: Load balancing scheme in local coordination-based routing.

\subsubsection{Multi-hop Single-transceiver Cognitive}

Radio Networks Routing Protocol (MSCRP):

MSCRP is an on demand routing protocol based on ad hoc on demand distance vector (AODV). In MSCRP [8], there is no common control channel. Hence routing protocol messages are exchanged without common control channel. Every node is not aware of the channel set of the other nodes, hence modifications are necessary to AODV to form an interaction for exchanging the available information among network nodes. By broadcasting Route Request (RREQ), nodes initiate route discovery procedure. RREQ must be broadcasted on all available channels as different nodes stay on different channels. The information of available channels is piggybacked by RREQ messages. The intermediate/relay nodes include its state and working channel information, while forwarding RREQ packet. So when a node receives a RREQ, it knows the working channels of nodes on the path the RREQ passing through. Then same as that of AODV, the nodes set up a reverse path to node S. After receiving RREQ, The destination node knows the available channel information of all nodes on the path and assigns a channel for this flow. It then sends back a Route Reply (RREP) to the source, with enclosing the assigned channel. . This RREP should be sent on the working channel of pre-hop. In MSCRP, Ma et.al first introduced the deafness problem which occurs due to channel switching. The two nodes are listening on different channels; hence they may not be able to communicate with each other. To avoid the deafness problem, two consecutive nodes in a flow cannot be in switching state simultaneously, one of them has to stay on one channel. As communication with a switching node is difficult, LEAVE/JOIN messages are used for giving information to the neighbors of switching nodes' working channel. MSCRP is a cross layer protocol, so it identifies six system functions as follows:

Spectrum sensing, detecting active primary user and estimating the quality of available channels, which are the functions performed at the physical layer. Routing and scheduling in the multi-flow and multi-channel environment are performed at network layer. Last one is IEEE 802.11 DCF is used as the MAC protocol, which is performed at link layer.

\subsection{Local coordination-based routing:}

Local coordination-based routing [15] is also a continuation work of SORP. In this, the modification is done to perform load balancing, using a local coordination scheme on intersecting nodes. In this protocol, the local coordination scheme is called up at the time when a node becomes an intersecting node to accommodate multiple data flows. This 
scheme helps intersecting nodes to decide whether to perform flow accommodation or flow redirection based on workload evaluation (includes additional control packet exchanges). As shown in figure 5 , flow 2 is served by node 1 , and flow 3 is served by node 2 . When new flow 1 occurs, first it is established with node 1 and node 2 as intermediate nodes. These two intersecting nodes perform a local coordination scheme to find appropriate neighbors to redirect the flow. The results are as follows: flow 1 is redirected by node 1 , to neighboring node 3 , and flow 3 is redirected by node 2 , to neighboring node 4 .

In local coordination, switching nodes are created side by side , due to the load balancing between the nodes while redirecting the flows to neighboring nodes. Thus two consecutive nodes serving the same flow are switching nodes in this scenario; hence the deafness problem constraints are disagreed. Local coordination-based routing results in low cumulative delay.

\subsection{Tree based Routing:}

Tree based routing is centralized routing scheme which is controlled by a single network entity called base station. In tree based routing protocol a tree structured network is formed in which cognitive base station is treated as root. In the subsections below, tree based routing protocols are discussed and summarized.

\subsubsection{Cognitive Tree-based Routing (CTBR)}

The Cognitive Tree-based Routing (CTBR) is an efficient and practical protocol [17], which extends and significantly enhances the ability of the known TBR protocol proposed for the wireless mesh networks [18-19]. The original Tree-based Routing (TBR) protocol only works on a single wireless system such as IEEE802.11a or $11 \mathrm{~b}$, rather than multiple wireless systems as proposed CTBR can in CRNs. In CTBR protocol each Cognitive Transceiver (CT) are used which maintains a routing table based on the tree-structure to root, which allows it to forward data packets via root, destined for the other nodes in the cognitive network. Cognitive tree-based routing (CTBR) protocol was proposed as an extension of tree based routing, which is taking the cognitive radio base-station as root.

Routing procedure of CTBR includes Root Announcement (RANN) message for tree formulation, same as that of TBR in which root periodically sends Root Announcement (RANN) message for forming the tree. A tree-structured network is formed by configuring the Cognitive Base Station (CBS) as a root in a cognitive wireless networks. When the root is configured, all CTs maintain routing information to the root. Any CT receiving the RANN caches the CT it received the announcement from as the potential parent. To precisely calculate the total local link metric with multiple interfaces, every CT needs to wait for a pre-define time for other RANN arriving from other interface. After the period is expired, the CT rebroadcasts the RANN through all of interfaces with an updated link metric. In addition, the CT selects a parent CT with the best-metric for the path to the root from all potential parents. To register itself with the root, every CT sends a RREP message destined to the root with its stored sequence number when it heard the RANN from the parent CT. Each intermediate CT that received the RREP forwards the message to its selected parent CT, and at the same time updates its route table with the source CT of RREP as the destination address. At the end, the root can learn all CTs, and build a tree topology to reach any $\mathrm{CT}$ in the cognitive network.
The main feature of CTBR includes Global and Local Decision Schemes of CTBR, in which each CT maintains a routing table based on the tree-structure to root, which allows it to forward data packets via root, destined for the other nodes in the cognitive network. Route table entry is uniquely defined for pairs of source and destination, to avoid concentrating all traffics to a common destination from different sources on an identical route. Each CT calculates the sum of the local cognitive-aware link metric for every sourcedestination pair, and selects a best route with the best end-toend route metric. Multi-path is held when route metrics for different paths with the same source-destination pair have the same amount. Root flag is added in the routing table. In case of multiple choices, the end-to-end route is determined based on a local route decision scheme.

\subsubsection{Spectrum-Tree based On-Demand Routing Protocol (STOD-RP):}

STOD_RP [20] is the protocol used to solve the problem of cooperation between spectrum decision and route selection; its framework can be shown as in the figure below (Figure 6). For which a spectrum-tree is build in each spectrum band. A spectrum tree is formed using secondary users (SUs) in each available spectrum band. Each spectrum-tree has one root. Some nodes may belong to multiple spectrum-trees, called overlapping nodes or gateway nodes. In one spectrum tree each node has its unique cognitive radio identifier CRID. Hence, the overlapping nodes that work in multiple spectrum bands have multiple CRIDs. Thus, CRID indicates the proactive route to the root node. The STOD-RP is a hybrid routing protocol which combines tree-based proactive routing and on-demand route discovery that is an extension of the original AODV [10].

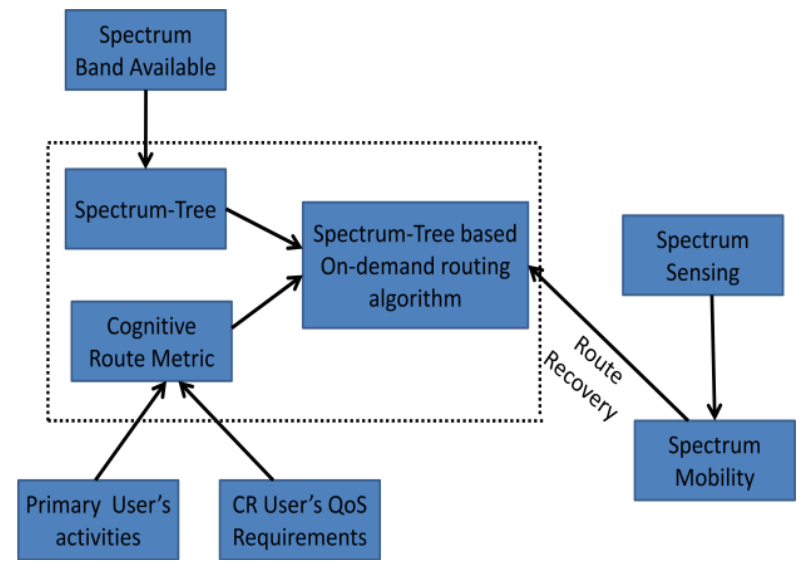

Fig 6: STOD-RP framework

Routing in STOD-RP is classified into intra-spectrum routing and inter-spectrum routing. To obtain a route for data transmission between the source and the destination, the protocol runs tree-based proactive routing to find a root node and then triggers on-demand route discovery to search the destination. The route discovery process uses a spectrum route request (SRREQ) and a spectrum route reply (SRREP). AODV's RREQ is extended in SRREQ with the fields [CRIDS, CRIDD, metric, intra/inter], and AODV's RREP is extended in SRREP with the fields [CRIDS, CRIDD, intra/inter]. [CRIDS] and [CRIDD] are the CRIDs of the source node and destination node, respectively. [metric] is the cumulative cognitive route cost, and [intra/inter] indicates that the destination node is present in the same spectrum-tree as the source node or not . It is proved using simulation results 
that STOD-RP reduced the average end-to-end delay with the increased number of gateway nodes (the nodes which belong to multi spectrum-trees), as compare to CTBR.

\subsection{Spectrum aware routing protocols:}

The objective of spectrum aware routing is to opportunistically route data packets, across paths with underutilized spectrum, avoiding congested (in terms of spectrum availability) areas. In Dynamic spectrum-aware routing protocols, unallocated wireless spectrums are utilized by Cognitive Radio (CR) nodes in the efficient manner.

In such routing protocols route discovery includes spectrum sensing. The main aim of such protocols is to find out and maintain the route across the available spectrum bands. Following subsections summarizes these protocols.

\subsubsection{Spectrum Aware Routing Protocol for Cognitive Ad-Hoc Networks (SEARCH):}

SEARCH [21] is the protocol which considers the path and the channel selection together to avoid the regions of the Primary User's activities while forming a route. The SEARCH protocol uses the geographic forwarding [21]. Geographic forwarding is used for finding the optimal path which minimizes the hop count to reach to the destination. For improving route selection, three main functions are performed in this protocol: - (1) Route Setup (2) Joint Channel -Path optimization and (3) Route Enhancement. In (1) Route Setup function, a route request packet (RREQ) is transmitted by the source to all the nodes of the channel which is not affected by the PU activity. The packet will be forwarded until it reaches the destination, and the relay/ intermediate nodes adds four fields (a) ID, (b) its current location, (c) TTL and (d) flag (to indicate the propagation mode of the algorithm used) with the RREQ packet. Two methods used for Route Setup are: Greedy Forwarding and PU Avoidance. In Greedy Forwarding, RREQ will be forwarded on the same channel and the next hop will not be on the PU coverage region. The relay must be present in the specific region around the current hop. In the PU Avoidance, if a PU region is interrupted then the present channel cannot be used effectively and the RREQ gets surround around the affected region. In (2) Joint Channel -Path optimization mainly five steps are performed (i) Initial Path Selection (ii) Greedy Path Formation (iii) Decision point optimization (iv) Route Expansion (v) Route Confirmation. In (i) Initial Path Selection, The RREQs from different channels are obtained by the destination node which extracts the path information from all the RREQs. The path, $p$, contains a set of nodes with their own timestamps. In the second step, (ii) Greedy Path Formation, the decision points are considered to improve the quality of the route by intersecting the paths on the other channels. This protocol is trying to improve the quality of the route. A route which has a shorter route to the destination is considered as the better route, which is from different channels. If the next hop happens to be the final destination, then the decision follows the Route Confirmation step and the path is found, otherwise again the Decision point optimization is needed. In third step, that is (iii) Decision point optimization step, once the decision point is reached, the protocol finds the intersecting path of different channels on the same location. For example, a given path $\mathrm{P} 1$ with the node $\mathrm{x}$ is said to be intersecting with another path $\mathrm{P} 2$, if it has a common node in common or it has a node within the transmission range of node of P1.In step (iv) Route Expansion , the optimal path is updated with the new channel and more information about the path. The final path includes the channel switching decisions and the allowed distance between any two nodes in the network [21]. Finally in the last step, (v) Route Confirmation, after reaching to the destination, the route reply (RREP) packet is sent back to the source on the optimal path. RREP includes the identification number of the individual node, their current location, and the channel switching decisions. The data transmission will be started immediately after the reception of the RREP packet from the destination. The third main function followed by SEARCH protocol is (3) Route Enhancement function. In Route Enhancement, several paths formed on different channels are linked together that are up to " $n$ " hops away. Algorithm for Route Enhancement can be written as follows:

1. All possible paths are checked at each Decision Point (DP), in the Route Setup function. DP is considered as the current path, if none of the node is within the transmission range of the source. So, the currently identified shortest path can be further optimized by considering all other DPs, and the linking or communicating locations on other paths or channels which with their transmission range.

2. A Route Enhancement (ROP) message is sent by the destination to the recent DP, after discovering the feasible path. The ROP message consists of ID of the recent node which is on the new path and the path information.

3. A RREQ message is sent by the DP, which receives the ROP message and acts as a source, to another node which is considered as the destination. The process is similar to the route setup phase involving the greedy finding. For RREP message, the route information received from the ROP is used.

4. The destination checks the delay of the path which has to be less than the current one, after receiving the RREQ. If it is less than the current one, the destination node generates the RREP message and forwards it to the source. It also generates the RERR message, if there is route failure while transmitting the data.

5. This process of run - time optimization is performed till finding out the optimal path with minimal delay.

\subsubsection{Spectrum and Energy Aware Routing (SER) Protocol}

SER [22] protocol is used mainly in the small CR networks in which the low topological changes are found. Its main aim is to develop a bandwidth guaranteed QoS routes. The QoS requirement considered here is the number of transmission timeslots for a packet on its route from source to reach the destination. This protocol uses Time Division Multiple Access (TDMA). Its Route Discovery procedure includes the route request (RREQ) broadcast procedure which is based on Dynamic Source Routing Protocol (DSR)[23]. Source CR user $\left(\mathrm{CR}_{\text {source }}\right)$ starts the route discovery process by broadcasting a spectrum aware RREQ message on the Common Control Channel (CCC), when it has packets to send to the destination $\mathrm{CR}$ user $\left(\mathrm{CR}_{\text {desti }}\right)$, all the neighbors of $\mathrm{CR}_{\text {source }}$ gets the RREQ message. An intermediate $\mathrm{CR}$ user, say I, which uses a timer, once it receives the first RREQ for each received RREQ from the neighbor, say $\mathrm{N}$, before the timer expires, I runs the communication segment assignment algorithm to find the feasible communication segments between the link. i.e. $1=(\mathrm{N}, \mathrm{I})$. If the feasible communication segment is not found, $\mathrm{N}$ drops the corresponding RREQ. Else, 
the link attaches itself to the current partial path, updates the other information and rebroadcast it. At the same time, the value of the hop count and the time to live[22] is increased by the Cognitive user.

The destination user waits for more RREQs to arrive at its side. A timer is also set by the destination user on its side, for the purpose of monitoring the multiple RREQs. For selecting the optimal path, the destination will use the same technique as that of the source node. It determines the route by using the utility route of the path and selects the one which is used to the maximum. Using the same control channel, the destination replies the source CR user with route reply (RREP) packet. The communication segment of each link for the path is used especially only for the data transmission, which is a reserved one. All the intermediate users' reserves the same communication segment mentioned in the route reply packet whenever the RREP is forwarded towards the source CR user. There may be problem of intersecting path from other communication segment too, hence the communication segment assignment algorithm coordinates the conflicting users with it $\mathrm{s}$ one - hop neighbors scheduling to recover the route reservation instead of finding a new route. After receiving the Route Reply by the destination, the data transmission begins, in which the data will be forwarded by the source to the destination via the intermediate CR users. The route maintenance happens automatically by using route recovery (RREC) and route error (RERR) messages.

\subsection{Multi Path based Routing}

To minimize the effect of appearance of primary users, multipath routing is used, assuming that there is a provision of multiple radios at each station. The multipath routing protocols find out multiple routes between a pair of source and destination in order to have load balancing to satisfy Quality of Service (QoS) requirements. Multipath routing protocols have a relatively greater ability to reduce the route discovery frequency than single path protocols. From the discovered routes some best routes are selected based on different parameters. In the following sub sections, multi-path routing protocols are discussed with its routing techniques.

\subsubsection{Multipath Routing and Spectrum Access (MRSA)}

To match with the CR environments, two main factors are to be considered, which are (i) dynamic spectrum availability and (ii)the imbalanced coexistence between PUs and SUs. Existing multi-path routing protocols may not be able to adapt to $\mathrm{CR}$ environments. These protocols uses a simple data striping mechanism like SMR [24], which divides data packets into multiple paths equally and transmits them in a round robin fashion over the multiple paths, which is not an effective technique. MRSA [25] is the first multi-path protocol for CRNs that minimizes the inter path contention and interference. In MRSA "spectrum wise disjointness" concept is revised as if multiple paths do not have any interfering bands between them then these paths are spectrum wise disjointed. In the route discovery process of MRSA, dynamic source routing (DSR) [23] mechanism is used in which at the initial stage the source node broadcasts an RREQ message with new RREQ_ID and attaches its band radio usage table (BRT). After receiving RREQ, the relay node, checks whether the RREQ_ID is new or not before forwarding it, if RREQ_ID is not new then it counts the hop count from source. If RREQ has fewer hop count than the previous RREQ it will append its BRT and then forwards it. In this way, the destination will receive the same RREQ from multiple paths. Thus it first assigns band and radio to each link then examines all the candidate paths by their available bandwidth. For route recovery, the RERR message of DSR is extended to overcome the sudden appearance of PU.

\subsubsection{Ad Hoc On-Demand Multipath Distance Vector Routing (AOMDV) Protocol:}

AOMDV [26] is adopted from the well known on-demand single path protocol known as ad hoc on-demand distance vector (AODV)[10]. The main difference between AOMDV and AODV is in the number of routes found in each route discovery. In each route discovery, AOMDV finds the multiple paths between the source and the destination. A little additional overhead is required for the computation of multiple paths. This is done by adding few extra fields in the packet headers of AODV control packets. Multiple paths computed by this method provide the assurance to be loopfree and disjoint [27]. Following figure (figure 7) shows the working of AOMDV.

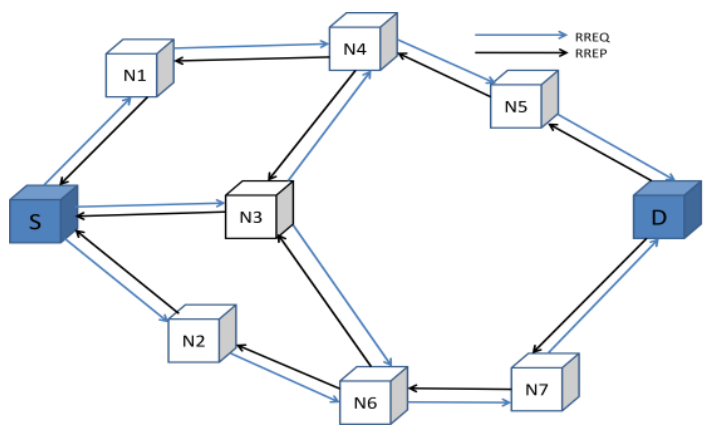

Fig 7: Working of AOMDV

The protocol broadcasts RREQ from source towards the destination. As shown in the figure, multiple RREQ are broadcasted. The node $\mathrm{S}$ is the source node which broadcasts multiple requests to its neighboring nodes 1 and 2 . This means that request with same sequence numbers are sent to the destination node. Then nodes 1 and 2 will broadcast the request to the other neighboring nodes, which are further sent to the destination node D. Broadcasting RREQ from the source towards the destination establishes multiple reverse paths both at relay nodes as well as the destination. To form multiple forward paths to the destination at the source and relay nodes, multiple RREPs traverse these reverse paths back. AOMDV also provides relay nodes with alternative paths as they are found to be useful in reducing route discovery frequency [28].

\section{SUMMARY OF THE ROUTING PROTOCOLS FOR CRNS 4.1 Summary of the On-Demand Routing Protocols:}

Following table (TABLE 1) shows the summary of SORP and MSCRP routing protocols: 
Table 1. The summary of SORP and MSCRP routing

\begin{tabular}{|c|c|c|}
\hline \multicolumn{3}{|c|}{ protocols } \\
\hline $\begin{array}{l}\text { Protocol } \\
\text { Name }\end{array}$ & SORP & MSCRP \\
\hline $\begin{array}{l}\text { Protocol } \\
\text { Type }\end{array}$ & On demand & On demand \\
\hline $\begin{array}{c}\text { Route } \\
\text { Discovery }\end{array}$ & $\begin{array}{c}\text { Broadcasts RREQ } \\
\text { messages }\end{array}$ & $\begin{array}{c}\text { RREQ massage is passed } \\
\text { on all available channels } \\
\text { instead of a single } \\
\text { channel }\end{array}$ \\
\hline $\begin{array}{l}\text { Modificati } \\
\text { on with } \\
\text { respect to } \\
\text { AODV }\end{array}$ & $\begin{array}{c}\text { Inserting } \\
\text { spectrum-related } \\
\text { information } \\
\text { (SOP),into the } \\
\text { routing control } \\
\text { packets. }\end{array}$ & $\begin{array}{l}\text { The intermediate/relay } \\
\text { nodes includes its state } \\
\text { and working channel } \\
\text { information. }\end{array}$ \\
\hline $\begin{array}{c}\text { Selecting } \\
\text { the Best } \\
\text { Path }\end{array}$ & $\begin{array}{l}\text { Switching delay } \\
\text { and back off delay }\end{array}$ & $\begin{array}{l}\text { Number of flows on each } \\
\text { channel }\end{array}$ \\
\hline $\begin{array}{l}\text { Handling } \\
\text { the link } \\
\text { failure }\end{array}$ & Not possible & $\begin{array}{c}\text { With the help of } \\
\text { LEAVE/JOIN messages }\end{array}$ \\
\hline Advantage & $\begin{array}{l}\text { Suitable for delay- } \\
\text { sensitive } \\
\text { application }\end{array}$ & $\begin{array}{l}\text { Solves the deafness } \\
\text { problem }\end{array}$ \\
\hline $\begin{array}{l}\text { Disadvant- } \\
\text {-age }\end{array}$ & $\begin{array}{l}\text { Does not include } \\
\text { PU avoidance }\end{array}$ & $\begin{array}{l}\text { Adds node networking } \\
\text { tasks }\end{array}$ \\
\hline
\end{tabular}

\subsection{Summary of the Local Coordination-}

\section{based Routing:}

Following table (TABLE 2) shows the summary of Local coordination-based routing:

Table 2. The summary of Local coordination-based

\begin{tabular}{|c|c|}
\hline \multicolumn{1}{|c|}{ Protocol Name } & LCB routing protocol \\
\hline Protocol Type & Local coordination-based \\
\hline Route Discovery & Broadcasts RREQ messages \\
\hline $\begin{array}{c}\text { Load Balancing } \\
\text { Best Path }\end{array}$ & A local coordination scheme is used \\
\hline $\begin{array}{c}\text { Handling the } \\
\text { link failure }\end{array}$ & Redirecting flow to another neighbor \\
\hline Advantage & Low cumulative delay \\
\hline Disadvantage & Adds control packet exchanges \\
\hline
\end{tabular}

\subsection{Summary of the Tree based Routing Protocols:}

Following table (TABLE 3) shows the summary of CTBR and STOD-RP routing protocols:

Table 3 .The summary of CTBR and STOD-RP routing protocols

\begin{tabular}{|c|c|c|}
\hline $\begin{array}{c}\text { Protocol } \\
\text { Name }\end{array}$ & CTBR & STOD-RP \\
\hline $\begin{array}{c}\text { Protocol } \\
\text { Type }\end{array}$ & Tree Based & $\begin{array}{l}\text { Hybrid (Combine } \\
\text { Tree-based and } \\
\text { On-demand ) }\end{array}$ \\
\hline $\begin{array}{c}\text { Route } \\
\text { Discover } \\
\mathbf{y}\end{array}$ & $\begin{array}{l}\text { Broadcasts Root } \\
\text { Announcement } \\
\text { (RANN) message }\end{array}$ & $\begin{array}{l}\text { SRREQ with the } \\
\text { fields [CRIDS, } \\
\text { CRIDD, metric, } \\
\text { intra/inter] }\end{array}$ \\
\hline $\begin{array}{c}\text { Selecting } \\
\text { the Best } \\
\text { Path }\end{array}$ & $\begin{array}{l}\text { On the basics of } \\
\text { global and local } \\
\text { decision schemes } \\
\text { best path is selected }\end{array}$ & $\begin{array}{c}\text { Establishes a } \\
\text { spectrum-tree in } \\
\text { each spectrum } \\
\text { band }\end{array}$ \\
\hline $\begin{array}{l}\text { Handlin } \\
\text { g the } \\
\text { link } \\
\text { failure }\end{array}$ & Not possible & $\begin{array}{c}\text { Applying the } \\
\text { spectrum handoff } \\
\text { and path rerouting } \\
\text { methods }\end{array}$ \\
\hline $\begin{array}{c}\text { Advanta } \\
\text {-ge }\end{array}$ & $\begin{array}{l}\text { Packet delivery } \\
\text { ratio is increased by } \\
\text { about } 40 \% \text { over the } \\
\text { hop-count based } \\
\text { scheme }\end{array}$ & $\begin{array}{l}\text { Simulation result: } \\
\text { reduces end-to- } \\
\text { end delay and } \\
\text { control overhead }\end{array}$ \\
\hline $\begin{array}{l}\text { Disadva- } \\
\text {-ntage }\end{array}$ & $\begin{array}{l}\text { The performance of } \\
\text { STBH is better than } \\
\text { CTBR by the } \\
\text { consideration of } \\
\text { End to End Average } \\
\text { Delay (E2EAD). }\end{array}$ & $\begin{array}{l}\text { Lacks analysis of } \\
\text { gateway node } \\
\text { activity (e.g. } \\
\text { energy } \\
\text { consumption) }\end{array}$ \\
\hline
\end{tabular}

\subsection{Summary of the Spectrum Aware Routing Protocols:}

Following table (TABLE 4) shows the summary of SEARCH and SER routing protocols:

Table 4. The summary of SEARCH and SER routing

\begin{tabular}{|c|c|c|}
\hline $\begin{array}{c}\text { Protocol } \\
\text { Name }\end{array}$ & SEARCH & SER \\
\hline $\begin{array}{c}\text { Protocol } \\
\text { Type }\end{array}$ & Spectrum aware & $\begin{array}{c}\text { Spectrum and Energy } \\
\text { aware }\end{array}$ \\
\hline $\begin{array}{c}\text { Route } \\
\text { Discover }\end{array}$ & $\begin{array}{c}\text { Greedy } \\
\text { Forwarding and } \\
\text { PU Avoidance }\end{array}$ & $\begin{array}{c}\text { Common control } \\
\text { channel used for } \\
\text { broadcasting the } \\
\text { Route Request } \\
\text { message }\end{array}$ \\
\hline
\end{tabular}




\begin{tabular}{|c|c|c|}
\hline $\begin{array}{c}\text { Working } \\
\text { of the } \\
\text { protocol }\end{array}$ & $\begin{array}{c}\text { It is based on } \\
\text { Geographic } \\
\text { routing, which is } \\
\text { based on the } \\
\text { dynamic } \\
\text { spectrum } \\
\text { availability and } \\
\text { the node } \\
\text { mobility. }\end{array}$ & $\begin{array}{c}\text { Energy efficient route } \\
\text { is selected and } \\
\text { channels and } \\
\text { timeslots are assigned } \\
\text { for the connection } \\
\text { request }\end{array}$ \\
\hline $\begin{array}{c}\text { Selecting } \\
\text { the Best } \\
\text { Path }\end{array}$ & $\begin{array}{c}\text { Joint channel - } \\
\text { path optimization } \\
\text { algorithm }\end{array}$ & $\begin{array}{c}\text { It used to increase the } \\
\text { lifetime of the CR } \\
\text { user individually. } \\
\text { Increases the } \\
\text { throughput and end - } \\
\text { to end latency }\end{array}$ \\
& & \\
\hline
\end{tabular}

\subsection{Summary of the Multi-Path based}

\section{Routing Protocols:}

Following table (Table 5) shows the summary of MRSA and AOMDV routing protocols:

Table 5. The summary of MRSA and AOMDV routing protocols

\begin{tabular}{|c|c|c|}
\hline $\begin{array}{l}\text { Protocol } \\
\text { Name }\end{array}$ & MRSA & AOMDV \\
\hline $\begin{array}{l}\text { Protocol } \\
\text { Type }\end{array}$ & Multi-path & Multi-path \\
\hline $\begin{array}{c}\text { Route } \\
\text { Discover } \\
\mathbf{y}\end{array}$ & $\begin{array}{c}\text { Control channel, } \\
\text { Broadcasting RREQ } \\
\text { message }\end{array}$ & $\begin{array}{l}\text { Multiple RREQ are } \\
\text { broadcasted }\end{array}$ \\
\hline $\begin{array}{l}\text { Workin } \\
\text { g of the } \\
\text { protocol }\end{array}$ & $\begin{array}{l}\text { Minimizes the inter } \\
\text { path contention and } \\
\text { interference. In } \\
\text { MRSA "spectrum } \\
\text { wise disjointness" } \\
\text { concept is revised }\end{array}$ & $\begin{array}{l}\text { Computes multiple } \\
\text { loop-free and link- } \\
\text { disjoint paths. }\end{array}$ \\
\hline $\begin{array}{c}\text { Path } \\
\text { failure } \\
\text { handling }\end{array}$ & $\begin{array}{c}\text { Used RERR } \\
\text { messages }\end{array}$ & $\begin{array}{l}\text { A node generates or } \\
\text { forwards a RERR for a } \\
\text { destination when the } \\
\text { last path to the } \\
\text { destination breaks. It } \\
\text { also includes an } \\
\text { optimization to salvage } \\
\text { packets forwarded over } \\
\text { failed links by re- } \\
\text { forwarding them over } \\
\text { alternate paths. }\end{array}$ \\
\hline $\begin{array}{l}\text { Selectin } \\
\text { g the } \\
\text { Best } \\
\text { Path }\end{array}$ & Minimum hop count & $\begin{array}{l}\text { Route carrying the } \\
\text { minimum hop count } \\
\text { value is selected }\end{array}$ \\
\hline $\begin{array}{c}\text { Advanta } \\
\text { ge }\end{array}$ & $\begin{array}{l}\text { The protocol } \\
\text { constructs multiple } \\
\text { paths to maximize } \\
\text { spectrum wise } \\
\text { disjointedness and to } \\
\text { minimize contention } \\
\text { and interference. }\end{array}$ & $\begin{array}{l}\text { AOMDV allows } \\
\text { intermediate nodes to } \\
\text { reply to RREQs, while } \\
\text { still selecting disjoint } \\
\text { paths }\end{array}$ \\
\hline
\end{tabular}

\section{CONCLUSION}

Cognitive radio technology has been proposed as an advanced solution towards more efficient utilization of the insufficient spectrum resources in an adaptive and intelligent way. The dynamic spectrum changing pattern of the devices enabled with cognitive radio capabilities makes routing a challenging job. In this paper, firstly the types of networks, that is infrastructure based and infrastructure less CRNs are discussed. Then the four main challenges for routing in CRN are discussed which are, Link Availability, Unidirectional Links, Network heterogeneity and Deafness Problem. In the sense of efficient routing in the CR environment, many routing protocols are used with their good or not so good results. Some of the routing protocols which try to provide an efficient and effective routing in CRNs are discussed in this paper, which are classified on their operations such as On demand routing, Local coordination based routing, Tree based routing, Spectrum aware routing and Multipath based routing. Then according to their features, the summary of these routing protocols is presented in table format. Even though all these protocols are giving the better results, but these are using the routing metrics same as that of the previously used. Hence there is need to design new metrics which covers all the dynamic characteristics of CRNs and based on these metrics novel routing scheme should be presented.

\section{ACKNOWLEDGMENTS}

I would like to express my sincere gratitude to my Prof. Sunita Barve, MIT Academy of Engineering, India, under whose supervision this research was undertaken.

\section{REFERENCES}

[1] FCC, ET Docket No 03-222 Notice of proposed rule making and order, December 2003.

[2] DARPA XG WG, The XG Architectural Framework V1.0,2003.

[3] DARPA XG WG, The XG Vision RFC V1.0, 2003.

[4] Kaushik R. Chowdhury,F.Akyildiz,"CRP:A Routing Protocol for Cognitive radio Ad Hoc Networks",IEEE Journal on Selected Area in Comm.,Vol. 29,no. 4,April 2011.

[5] Geng Cheng, Wei Liu, Yunzhao Li, and Wenqing Cheng, "Joint On-demand Routing and Spectrum Assignment in Cognitive Radio Networks, "IEEE JCC 2007.

[6] De Cout, D. S. J, et.al. A high-throughput path metric for multihop wireless routing. In Proc. Of MobiCom (Sept. 2003).

[7] Kwang-Cheng, Chen, Ramjee Prasad, "Cognitive radio networks". 2009 John Wiley \& Sons Ltd. ISBN: 978-0470-69689-7.

[8] Ma, H. and Zheng, L. and Ma, X. and Luo," Spectrumaware routing for multi-hop cognitive radio networks with a single transceiver", Proceedings of the Cognitive Radio Oriented Wireless Networks and Communications (CrownCom) 2008.

[9] Yang Xiao, Fei Hu "Cognitive radio networks". 2009 Taylor \& Francis Group, LLC. ISBN: 978-1-4200-64209 
[10] C Perkins, E Belding-Royer, Ad hoc on-demand distance vector (AODV) routing. (IETF RFC 3561, 2003). http://www.ietf.org/rfc/rfc3561.txt. Accessed 24 January 2011.

[11] D Johnson, Y Hu, D Maltz, The dynamic source routing protocol (DSR) for mobile ad hoc networks for Ipv4. (IETF RFC 4728, 2007). http://www.ietf.org/rfc/rfc4728.txt. Accessed 24 January 2011.

[12] G Cheng, W Liu, Y Li, W Cheng, Spectrum aware ondemand routing in cognitive radio networks, in Proceedings of the 2nd IEEE International Symposium on New Frontiers in Dynamic Spectrum Access Networks (Dublin,17-20 April 2007)

[13] G Cheng, W Liu, Y Li, W Cheng, Joint on-demand routing and spectrum assignment in cognitive radio networks, in Proceedings of the IEEE International Conference on Communications (Glasgow, 24-28 June 2007).

[14] C Perkins, E Royer, Ad-hoc on-demand distance vector routing. Proceedings of the 2nd IEEE Workshop on Mobile Computing Systems and Applications (New Orleans, 25-26 February 1999)

[15] Z Yang, G Cheng, W Liu, W Yuan, W Cheng, Local coordination based routing and spectrum assignment in multi-hop cognitive radio networks. Mobile Network. Appl. 13, 67-81 (2008).

[16] B. Zhang, Y. Takizawa, A. Hasagawa, A. Yamauchi, and S. Obana, "Tree-based routing protocol for cognitive wireless access networks," in Proc. of IEEE Wireless Communications and Networking Conference2007

[17] Wang, X. and Kwon, T.T. and Choi," A multipath routing and spectrum access (MRSA) framework for cognitive radio systems in multi-radio mesh networks" Proceedings of the 2009 ACM workshop on Cognitive radio networks 2009.

[18] IEEE 802.11s http://www.802wirelessworld.com/

[19] A. Raniwala and T. C. Chiueh, "Architecture and algorithms for an IEEE802.11-based multi-channel wireless mesh network," in Proc. IEEE INFOCOM Conf., pp.2223-2234, 2005.

[20] G Zhu, IF Akyildiz, G Kuo, STOD-RP, A spectrum-tree based on-demand routing protocol for multi-hop cognitive radio networks, in Proceedings of the IEEE Global Telecommunications Conference (, New Orleans, 30November-4 December 2008)

[21] K.R. Chowdhury, M. Di Felice, "SEARCH : A routing protocol for mobile cognitive radio ad-hoc networks", SARNOFF"e 09,IEEE Sarnoff Symposium, pp 1-6, 2009.

[22] S.M Kamruzzaman, Eunhee Kim, Dong Geun Jeong, “ Spectrum and energy aware routing protocol for cognitive radio ad hoc networks", IEEE International Conference on Communications, pp 1-5, 2011.

[23] N2: D. B. Johnson, D.A. Maltz and Y. C. Hu, "The Dynamic Source Routing for mobile ad hoc networks,", draft-ietf-manet-dsr-09.txt, 2003.

[24] Sung-Ju Lee and Mario Gerla. Split multipath routing with maximally disjoint paths in ad hoc networks. In Proceedings of IEEE ICC, 2001.

[25] Wang, X. and Kwon, T.T. and Choi,” A multipath routing and spectrum access (MRSA) framework for cognitive radio systems in multi-radio mesh networks" Proceedings of the 2009 ACM workshop on Cognitive radio networks 2009 .

[26] H.D.Trung, W.Benjapolakul, P.M.Duc, -Performance evaluation and comparison of different ad hoc routing protocolsl, Department of Electrical Engineering, Chulalongkorn University, Bangkok, Thailand, May 2007.

[27] Z. J. Haas and M. R. Pearlman, -The Performance of Query Control Schemes for the Zone Routing Protocol, ACM/IEEE Trans. Net. 9 (August 2001)

[28] Nasipuri A, Castaneda R, Das SR. Performance of multipath routing for on-demand protocols in mobile ad hoc networks.ACM/Kluwer Mobile Networks and Applications (MONET)2001; 6(4): 339-349. 